\title{
Historia
}

\section{A 30 años de la caída de la URSS}

\section{Patricia Kreibohm ${ }^{1}$}

* Cómo citar este artículo: Kreibohm, P. (2021). A 30 años de la caída de la URSS.

Relaciones Internacionales, 30(60), 127. https://doi.org/10.24215/23142766e127

Han pasado ya treinta años desde que cayó la URSS: una caída que nadie previó ni imaginó, porque su existencia -arraigada en el planeta desde hacía 69 años- parecía ser parte estructural de la realidad planetaria, una parte absoluta e inmutable que perduraría para siempre. Sin embargo, la implosión de ese "otro mundo" llegó el 31 de diciembre de 1991 y cambió por completo la anatomía y la fisiología de las relaciones internacionales.

La URSS fue un Estado multinacional y pluriestatal -compuesto por más de 100 nacionalidades- que nació en 1922, cuando finalizó la guerra civil. En esa difícil circunstancia, Lenin consideró necesario fortalecer el poder del gobierno bolchevique en la Rusia comunista pero también sobre una serie de regiones que habían pertenecido al imperio del zar y que eran vitales para sus intereses.

En 1918, la guerra civil, amenazó sistemáticamente la consolidación del poder de los bolcheviques. Esto condujo a Lenin a crear un Comisario del Pueblo para las Nacionalidades, cargo en el que se designó a Joseph Stalin. En principio, este comisario debía velar por el respeto y la autonomía de cada una de las regiones. Sin embargo, años después, cuando los rojos ganaron la guerra, la política revolucionaria realizaría exactamente la acción contraria: el sometimiento y la rusificación. ${ }^{2}$

1 Magister en Relaciones Internacionales (Universidad Nacional de Tucumán), coordinadora del Departamento de Historia de las Relaciones Internacionales del IRI-UNLP

2 Service, Robert. Rusia en el siglo XX. Crítica. P. 120

Editor: Juan Alberto Rial, Instituto de Relaciones Internacionales Facultad de Ciencias Jurídicas y Sociales (Universidad Nacional de La Plata)
Entidad editora: Relaciones

Internacionales, es una publicación del Instituto de Relaciones Internacionales (Facultad de Ciencias Jurídicas y Sociales (Universidad Nacional de La Plata Argentina)

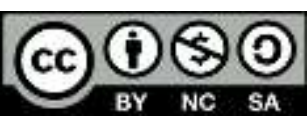

Reconocimiento-NoComercial Compartirlgual 4.0 Internacional (CC BY-NC-SA 4.0) 
De hecho, en vastas áreas del ex imperio, los rusos eran minoría y los bolcheviques carecían de un poder determinante. Muchas de ellas se habían declarado independientes después de la caída del zar y, si bien en principio Lenin había aceptado esta situación, veía con preocupación la separación de un conjunto de naciones que, no sólo eran significativas desde el punto de vista político, geopolítico y económico, sino que, además, podían convertirse en una amenaza hacia el futuro. Esto lo condujo a pensar que lo más adecuado era incorporarlas al modelo soviético. La finalización de la guerra civil y la victoria bolchevique, que no sólo se dio sobre los blancos, sino también sobre los territorios de otras repúblicas, le permitió al gobierno forzar la incorporación de algunas de ellas.

Así, en septiembre de 1922 Lenin estableció que tres repúblicas -Ucrania, Bielorrusia y Transcaucacia- formarían, junto con Rusia, una federación denominada: Unión de Repúblicas Socialistas Soviéticas (URSS). Esta medida fue ratificada en el I Congreso de los Soviets de la URSS, el 31 de diciembre de $1922 .^{3}$

Más adelante, y durante buena parte del siglo XX, el nuevo Estado soviético habría de experimentar una serie de ampliaciones, mediante las cuales el número de Estados incorporados a la URSS llegó a un total de quince.

La primera ampliación se dio en octubre de 1924, en función de la división de la República Socialista Autónoma de Turkestán, la cual formaba parte de la república socialista federativa de Rusia, y dio lugar a la creación de dos nuevas repúblicas: Uzbekistán y Turkmenistán.

En 1929, se sumó la República de Tayikistán y en 1936, la vieja República de Transcaucacia fue dividida en tres; así nacieron: Armenia, Azerbayán y Georgia. Poco después se agregaron Kazajistán y Kirguistán. ${ }^{4}$

En 1940, se creó la República Socialista Soviética de Carelia y, entre junio y julio del mismo año, en virtud del acuerdo Ribbentrop - Molotov, la URSS ocupó las tres repúblicas Bálticas:_Estonia, Letonia y Lituania.

La última incorporación fue la de Moldavia, que nació del territorio de Besarabia, anexado tras su ocupación por parte de la URSS.

Idenficadas bajo el modelo político-ideológico del Marxismo-Leninismo y sujetas a un sistema centralizado de Estado y Partido, cada una de ellas poseía un gobierno local, que obedecía al Soviet Supremo y al presidente de la URSS, y un partido comunista, que respondía a los lineamientos del PCUS.

Así, y durante décadas, la Unión Soviética se convirtió en el referente de muchos movimientos comunistas del mundo; se consolidó como uno de los polos hegemónicos de la segunda mitad del siglo XX, logró convertirse en una súper-potencia y, sobre todo, rivalizó con los EE.UU. y el bloque occidental, en un modelo de orden bipolar que condicionó

\footnotetext{
${ }^{3}$ Curiosamente fue el 31 de diciembre de 1991 cuando la URSS se autodisolvió.

${ }^{4}$ Esta república fue creada a partir de un desmembramiento de Uzbekistán.
} 
los contenidos, el tono y el ritmo de las relaciones internacionales hasta su colapso.

¿Pero, entonces, cómo y por qué desapareció?

\section{El proceso que condujo a la caída.}

Aproximadamente desde comienzos de los años 70, parecía que la URSS había entrado en un callejón sin salida. Ya en los 80 , y después del fallecimiento de Breznev y el ascenso de Andropov, la crisis económica, la carencia de alimentos y de productos de primera necesidad forzaron al gobierno a intentar realizar reformas para equilibrar la situación. Sin embargo, las medidas no dieron los resultados esperados y la conflictividad social se incrementó. Las primeras huelgas se iniciaron en las minas Kemerovo, en la cuenca de Kuz, y a ellas se sumaron las de Don, Karaganda, Kazajistán y Siberia. Paulatinamente los obreros se organizaron y pusieron al Estado en una situación crítica.

La falta de crecimiento económico, la desviación de un alto porcentaje del producto agrícola hacia el mercado paralelo, el ausentismo laboral elevado y la rigidez administrativa -con su enorme despilfarro de recursos- eran los elementos más obvios que llevaron a un sector del partido a buscar urgentemente un cambio estructural que corrigiese las desviaciones. Sin embargo, durante la presidencia de Chernenko esto no pudo concretarse, por lo que las expectativas del sector renovador recién comenzaron a tomar forma cuando Gorbachov asumió el poder en 1985.

¿Qué había fallado? En primer lugar, es evidente que uno de los principales problemas de la economía había sido la caída de la productividad del trabajo y la desaceleración del crecimiento que, en los últimos años, se había situado en el $1 \%$ anual, lo que era particularmente grave. En segundo lugar, la agricultura fue un problema que no pudo resolverse desde la época de Stalin. De hecho, en el mandato de Kruschev, se intentó modificar la situación a través del denominado "proyecto de las tierras vírgenes", pero las medidas que se adoptaron fueron inútiles, pues no se realizaron las inversiones adecuadas y, por tanto, la expansión de la frontera agrícola sólo agravó el problema. Por último, las negativas consecuencias de una administración excesivamente centralizada y burocratizada, reforzada durante el mandato de Breznev, se proyectaron sobre el conjunto de la economía soviética e, incluso, sobre la de los países del este europeo.

Así, en poco tiempo, los resultados fueron la falta de incentivos, la elusión de responsabilidades, el mantenimiento de empresas ineficaces (que sobrevivían con los beneficios de las empresas rentables), la lentitud de la transferencia tecnológica entre empresas y sectores productivos, y la absoluta inadecuación entre oferta y demanda. En definitiva, el producto material neto (sin incluir el sector de servicios) que creció al 4,3\% en el quinquenio $1976-1980$ creció solo al 3,3\% en el 81 , al $2,9 \%$ en el 84 , al $1,6 \%$ en el 85 , al $2,3 \%$ en el 86 y al $1,6 \%$ en el 87.

Este crecimiento declinante se complicó con problemas sociales y culturales de vieja data; problemas que pueden sintetizarse en cuatro conceptos: la fatiga social por la falta de estímulos personales y/o colectivos; las limitaciones de las expectativas individuales, 
profesionales o económicas; la desilusión por la corrupción generalizada y las prerrogativas de ciertos sectores (partido, funcionarios de la Nomenklatura y miembros de cuadros políticos y militares) y, finalmente, la falta de libertades.

Cuando Mijail Gorbachov llegó al poder, la situación era crítica. Impulsado por un genuino deseo de recuperar la URSS e inspirándose en las enseñanzas de Lenin, el mandatario intentó reformar la política y la economía a través de un programa ampliamente conocido: la Perestroika y la Glasnot. Sin embargo, la iniciativa no hizo más que profundizar el descontento y dividir una sociedad que se encontraba al borde del colapso. Aún más, en 1986 la explosión de la central de Chernobil produjo un desastre de una magnitud inimaginable, pero también puso al descubierto la incapacidad de la URSS para atender adecuadamente,cuestiones tan sensibles como las referidas a su armamento y a su aparato nuclear.

Hacia 1988, la división interna se profundizaba y distintos grupos y organizaciones políticas informales iniciaron un debate que llegó hasta el Congreso de los Diputados del Pueblo. Por su parte, las iglesias empezaron a ser frecuentadas por algunos creyentes. Los clérigos participaban en programas televisivos. Se inició la producción de una literatura cristiana y la Biblia volvió a ser vendida en las librerías. Poco a poco, la música pop se escuchaba en las radios y surgieron cantantes de rock que cuestionaban duramente al sistema.

La juventud no se rebelaba contra la autoridad; simplemente la despreciaba y la ignoraba. Para la mayoría, la política parecía un espectáculo deportivo que no merecía de la participación ciudadana. El desencanto y el cansancio eran cotidianos: la gente estaba harta de las largas colas, la escasez de comida, el caos administrativo, la mala calidad de los servicios públicos. En una palabra, la brecha que dividía a gobernantes y gobernados, se hacía cada vez más profunda y la opinión pública se distanciaba cada vez más de sus líderes. ${ }^{5}$

En junio de 1989, Estonia proclamó su autonomía económica y Letonia, su derecho a invalidar leyes de la URSS. Además, ambos Estados decidieron abandonar el idioma ruso, lo que dio lugar a que los miembros del Politburó los calificaran como un movimiento antisoviético y separatista.

En esos días, tanto rusos como no-rusos de toda la Unión sentían y manifestaban su insatisfacción creciente. A las divisiones internas de la URSS, entre partidarios del Comunismo Reformista de Gorbachov y partidarios del Comunismo Ortodoxo, se sumaba la acción de los disidentes: artistas, intelectuales y literatos, que empezaban a mostrar sus obras sin pudor. ${ }^{6}$ El comunismo perdía aceleradamente su reputación y las medidas implementadas por el presidente no hacían más que añadir dificultades. En poco tiempo, la política comenzó a ser objeto de la crítica pública; la autoridad central unificada se debili-

\footnotetext{
${ }^{5}$ Service. Op. Cit. P. 441

${ }^{6}$ Este es el caso de Archipiélago Gulag de Alexander Solyenitskin
} 
taba y las estructuras tradicionales se desmantelaban, sin ser reemplazadas por otras más consistentes.

Por su parte, en el resto de las repúblicas los problemas se acumulaban. A lo largo de su experiencia como Estados parte del sistema soviético, los nacionalismos -lejos de disolverse- se habían potenciado, haciendo que la lengua, la cultura y la historia se convirtieran en las banderas del rechazo a Moscú y de la revalorización de lo propio. Como sostiene Service, la manera leninista de organizar un Estado plurinacional mostraba finalmente toda su debilidad. "De hecho, otras repúblicas decidieron imitar la conducta de Letonia y de Estonia y, así, Azerbayán, Armenia, Georgia y Uzbequistán encabezaron protestas que hacían evidente que este Imperio sólo se mantenía por la fuerza". ${ }^{7}$

Poco después, Kazajistán y Tayikistán se sumaron a las protestas y, en septiembre de 1989, se despertó el gigante ucraniano. Todos los movimientos que se dieron durante el resto del año, iban en la misma dirección.

En octubre, Letonia reclamó su independencia y, en noviembre, la caída del muro de Berlín significó un golpe tremendo para el liderazgo soviético, que decidió no intervenir en el asunto. ${ }^{8}$ Dicho golpe, detonó a su vez dos procesos simultáneos que impactaron directamente sobre la URSS: la velocísima reunificación de Alemania y el desencadenamiento de una ola de revoluciones en los países de la Europa del Este.

En efecto, en la segunda mitad del año, los países europeos que conformaban el bloque soviético, se vinieron abajo uno por uno: Polonia, Hungría, la República Democrática alemana, Bulgaria, Checoslovaquia, Rumania. Así, las fichas del dominó, se derrumbaron precipitadamente...pero Gorbachov se encontraba tan absorbido por los problemas, que resolvió no intervenir. No pensaba sacarle las castañas del fuego a ninguno de sus aliados. El desenlace fue espectacular: a comienzos de 1989, los comunistas gobernaban todos los países de la Europa del Este. Al terminar el año, el único Estado comunista que quedaba era Albania. Es indudable que Gorbachov nunca previó que las cosas se dieran así. Este fue un resultado totalmente inesperado; sin embargo y en gran medida, fue obra suya. ${ }^{9}$

A esas alturas, la profunda preocupación de Gorbachov estaba totalmente justificada. La ola expansiva podía llegar a la URSS. Fue entonces cuando el mandatario insistió en la necesidad de crear un nuevo Estado de derecho y propuso incorporar a la legislación vigente un apartado referido a los derechos civiles. Asimismo, instó al Congreso de los Diputados y al Soviet Supremo a que abrieran espacios para que los secretarios locales del partido, los representantes de las Repúblicas, los encargados de las fábricas, los generales,

\footnotetext{
${ }^{7}$ Ibidem. Pp. 438 - 439

${ }^{8}$ Algunos especialistas denominaron a esta negativa de Gorbachov de intervenir en el problema de la RDA, como la Doctrina Sinatra: que cada uno haga, a su manera.

${ }^{9}$ Ibidem. Pp. 446 - 447
} 
los estudiosos y los mandos de la KGB manifestaran sus ideas. Esto facilitó que la población -a la que se le había negado toda información que se consideraba ofensiva o peligrosa para el régimen- se interesara vivamente en las cuestiones políticas. Curiosamente, la KGB ya no arrestaba a los ciudadanos que protestaban públicamente y había nacido una prensa independiente. En este contexto, las viejas élites empezaron a agruparse para defenderse. $^{10}$

En febrero de 1990, Gorbachov elaboró un Programa titulado Hacia un socialismo humano y democrático, uno de cuyos puntos sobresalientes apuntaba a lograr la liberación espiritual y política de la sociedad. Esto empeoró las cosas, pues vastos sectores políticos lo interpretaron como una ofensa al régimen. En ese mismo mes, logró que el Soviet Supremo aprobara un sistema pluripartidista y que el Congreso aceptara la imposibilidad de que el Politburó interviniera en asuntos de política interna. Los comunistas ortodoxos estaban cada vez más irritados. En octubre de ese año crearon una organización denominada Soyuz (unión) y se fijaron como meta detener el desastre que sufría la URSS.

Simultáneamente los sectores industriales, comerciales y financieros estaban al borde del colapso: el comercio se redujo a su mínima expresión, el Estado pidió préstamos a las potencias occidentales, y la importación de granos y bienes de consumo aumentó. La inflación se disparó, la comida y el combustible escaseaban, y el descontento social se incrementó de manera preocupante.

En 1990, Uzbekistán proclamó su independencia y, por iniciativa de Yeltsin, también lo hizo Rusia. En septiembre, le tocó el turno a Turkmenistán.

Meses después, ya en julio del 91, Gorbachov pidió créditos al Grupo de los Siete que se reunió en Londres. Para buena parte del público -que se burlaba del presidente y lo insultaba - esta fue una nueva afrenta: ahora la URSS hacía el papel de un mendigo pidiendo limosnas. "En realidad, muchos compartían la creencia de que la URSS era el Estado sucesor del Imperio Ruso. Estaban orgullosos de los logros industriales y culturales del país y se jactaban de haber derrotado a la Alemania Nazi. A su juicio, Gorbachov estaba destruyendo todo aquello y humillando a una gran sociedad."11

Un poco más adelante, el periódico Sovietskaya Rossiya, publicó la Carta al Pueblo, escrita por Nina Andreeva y firmada por una enorme cantidad de personas. Según Service, este documento se trataba, lisa y llanamente, de un manifiesto a favor de un golpe de Estado. "Ha ocurrido una desgracia sin precedentes. La Madre Patria, nuestro país, el gran Estado que la Historia, la Naturaleza y nuestros gloriosos antepasados nos han confiado, está pereciendo; se está deshaciendo, se está precipitando a la oscuridad y al olvido. Es imperativo que todos los ciudadanos, los Hijos de la Patria, ayuden a preservar a la URSS

\footnotetext{
${ }^{10}$ De hecho, el mayor temor del premier residía en que este desmembramiento se replicara fronteras dentro de la URSS. Para su desdicha, todas sus acciones lo ponían en ese camino. Aunque profundizó las reformas, siempre lo hizo a un ritmo mucho más lento que el de la crisis que envolvía al Estado, a la economía, a las Repúblicas, a la administración y al funcionariado.
}

11 Ibídem. P. 456 
de un final tan atroz". ${ }^{12}$

El golpe llegó en agosto de 1991. Duró apenas unos días y fracasó. Gorbachov fue liberado y repuesto en su cargo gracias a la oportuna intervención de Boris Yeltsin. Sin embargo, la URSS estaba herida de muerte.

Para 1991, Estonia, Letonia y Lituania solicitaron al resto del mundo su reconocimiento como Estados autónomos y soberanos, y en diciembre el pueblo ucraniano votó a favor en un referéndum por la independencia.

El 8 de diciembre, Yeltsin -el presidente de Rusia- propuso la creación de la Comunidad de Estados Independientes (CEI). Así, y en virtud del Tratado de Belovezh, se creó la CEI, una organización integrada por Rusia, Ucrania y Bielorrusia, destinada a mantener un espacio económico común y fuerzas armadas estratégicas unificadas entre los países miembro. El 21 de diciembre se agregaron ocho más: Armenia, Azerbayán, Kazajistán, Kirguizistán, Moldavia, Tayikistán, Turkmenistán y Uzbequistán.

Días después, el 26 de diciembre, el Soviet Supremo de la URSS reconoció el colapso y se autodisolvió. La URSS había desparecido. Su desarticulación oficial se ratificó el 31 de diciembre de 1991. En su discurso al dejar el cargo de secretario general, Gorbachov señaló: “Dejo mi puesto lleno de intranquilidad. Pero también con esperanza, con fe en vosotros, en vuestra sabiduría y en vuestra fuerza de espíritu. Somos los herederos de una gran civilización y ahora depende de todos nosotros que pueda resurgir y darnos una vida nueva, moderna y próspera." 13

Así se desmoronaba un Estado que había provocado temores políticos en el extranjero, desde el mismo momento en que nació, en 1917. Un Estado cuyas fronteras eran casi idénticas a las del Imperio Ruso y cuya población estaba integrada por una gran cantidad de naciones, religiones y filosofías. Un Estado que había desarrollado una poderosa industria y que había derrotado a Alemania en la IIa Guerra Mundial. Un Estado convertido en superpotencia y cuyo orden político y económico encarnó una categoría crucial del léxico del pensamiento del Siglo XX. A partir de 1992, ese Estado dejó de existir. ${ }^{14}$

\section{Las cuatro hipótesis de la caída.}

Desde la disolución de la URSS, los autores han debatido profundamente sobre este tema y, si bien está claro que los motivos que precipitaron la caída fueron muchos y complejos, han buscado establecer cuál fue su causa primordial. A continuación examinaremos

\footnotetext{
12 Ibídem. P. 460

${ }^{13}$ Ibidem. P. 468

${ }^{14}$ Ibidem. P. 469
} 
brevemente las cuatro hipótesis más importantes.

1. El germen de la autodestrucción estaba en el sistema desde el momento de su gestación. Según esta tesis, la destrucción sobrevendría más tarde o más temprano, pero era inevitable. En otras palabras, la URSS estaba destinada a desaparecer, pues tanto sus caracteres como sus lineamientos y sus mecanismos específicos, excesivamente rígidos, determinaban su discapacidad para adaptarse a los cambios y a las transformaciones de cada etapa histórica, sumiendo al sistema en una espiral de debilidad e inoperancia que terminó fagocitándose a sí mismo.

2. El factor Gorbachov. Para muchos autores, más allá de las buenas intenciones del premier soviético y de la legitimidad de su accionar, fueron sus decisiones y sus políticas las que precipitaron a la URSS en el abismo, básicamente porque un sistema tan rígido como el soviético no admitía cambios ni estaba en condiciones de flexibilizarse en ningún sentido. Cuando Gorbachov intentó transformarlo, sencillamente se quebró.

3. La Guerra Fría. Para los autores que suscriben esta postura, fue el enfrentamiento con los EE.UU. lo que desgastó -más allá de los límites- las capacidades económicas, tecnológicas e incluso políticas de la Unión Soviética. En efecto, tanto desde el punto de vista de los gastos y del esfuerzo que insumió a sus habitantes, como desde la perspectiva del poder, la Guerra Fría fue una prueba que la URSS no pudo superar y que no sólo le significó el atraso y el debilitamiento económico, sino que consumió sus energías políticas, económicas y morales hasta agotarla.

4. Las infiltraciones del capitalismo y el atraso tecnológico. En este caso se sostiene que, a pesar de todos los esfuerzos del régimen, el capitalismo se infiltró fronteras adentro y las poblaciones de la URSS alcanzaron a tener contacto con los productos, las ideas y las formas de vida de Occidente. Esta situación se agudizó a partir de los años 80 , cuando la tecnología alcanzó altos niveles de desarrollo. Así, las malas condiciones de vida y las privaciones a las que el pueblo soviético se vio sometido durante décadas contrastaron cada vez más con lo que parecía ser un mundo pleno de oportunidades; un mundo al que los habitantes soviéticos nunca tendrían acceso. Finalmente, el atraso tecnológico de la URSS fue decisivo y su referencia más palpable fue la carencia del desarrollo informático; una carencia que la dejó definitivamente fuera del mundo.

A partir de entonces, el mundo entró en una nueva etapa histórica en la que se produjeron una serie de transformaciones, cuyos efectos persisten hasta la actualidad. ${ }^{15}$ Como sostuvo Joseph Tulchin:

Al finalizar la Guerra Fría, la mayor parte de la gente esperaba que el mundo se convirtiera en un lugar más seguro y pacífico. Por más de 40

\footnotetext{
${ }^{15}$ En realidad, durante los primeros años de esta post-Guerra Fría, el mundo experimentó un gran alivio por la finalización del conflicto entre las dos grandes súper-potencias. Sin embargo, pronto se hizo evidente que los tiempos por venir estarían marcados por la incertidumbre y la ambigüedad.
} 
años, la Humanidad había vivido con la amenaza del holocausto nuclear... En consecuencia, cuando cayó la URSS, el sentimiento predominante fue de alivio... Sin embargo, la nueva era que ha empezado a emerger lentamente parece ser cualquier cosa menos ordenada $y$, ciertamente, no es pacífica. 